\title{
EXPERIMENTAL STUDY ON A FLAT PLATE COLLECTOR ASSISTED FOR SOLAR WATER HEATING UNIT
}

\author{
Fahim Ullah ${ }^{1,2}$, Mansoor Khan Khattak ${ }^{2}$, Min Kang ${ }^{1,3^{*}}$, Xiuqing $\mathrm{Fu}^{1}$, Niu \\ Hengtai ${ }^{1}$, Li Hengzheng ${ }^{1}$ and Ninghui $\mathrm{Li}^{1}$ \\ ${ }^{1}$ College of Engineering, Nanjing Agricultural University, Nanjing, 210031, P.R. China \\ ${ }^{2}$ Department of Agricultural Mechanization, FCPS, The University of Agriculture, KP- \\ Pakistan \\ ${ }^{3}$ Guanyun Research Institute for Modern Agricultural Equipment, Nanjing Agricultural \\ University, Guanyun, 222200, China
}

Corresponding Author: kangmin@njau.edu.cn

\begin{abstract}
Key words: Solar energy, Flat plate Collector, Efficiency and Heated water
Summary: The aim of the study was to develop Flat Plate Collector (FPC) from the locally available material in the market for the purpose of solar water heating. The efficiency of the collector was tested with the normal flow of water under ambient temperatures of $25^{\circ} \mathrm{C}$ for the consequently months of the year. The efficiency was noted $36.97 \%$ and $37.29 \%$ with the highest amount of absorbing solar irradiance from $4580 \mathrm{~kJ} \cdot \mathrm{m}^{-2} \cdot \mathrm{hr}^{-1}$ and $4365 \mathrm{~kJ} \cdot \mathrm{m}^{-2} \cdot \mathrm{hr}^{-1}$ for the month of June and July respectively. Results showed that the efficiency was increased significantly with the increasing of zenith and azimuth angle of the sun. From the results it was clearly showed that the collector gives maximum heated water from 16930 to 16277 1/month respectively due to the greater sun rays falling on the collector. It was observed from the experimental results, that water heated at a very fast rate with the highest amount of solar irradiance absorption with the highest efficiency of the collector and proves that FPC was the best technique to be used for the purposes of water heating.
\end{abstract}

\section{NOMENCLATURE}

\begin{tabular}{ccc}
\hline Symbol & Meaning & Unit \\
\hline FPC & Flat Plate Collector & - \\
SHW & Solar Water heating & - \\
P.V.C & Polyvinyl chloride & - \\
$I_{s}$ & Solar Irradiance & $\mathrm{kJ}^{-2} \cdot \mathrm{hr}^{-1}$ \\
$C_{v}$ & Chart Value & $\mathrm{Cal} . \mathrm{cm}^{-2} \cdot \mathrm{min}^{-1}$ \\
$\eta$ & Efficiency & $\%$ \\
$\pi$ & Content term & 3.14 \\
$R_{a b}$ & Radius of the absorber pipe and water tank & Meter \\
$L_{a b}$ & Length of absorber pipe and water tank & Meter \\
$V$ & Volume of the absorber pipe and water tank & Cubic meter \\
$Q$ & Daily output of heated water & Liter \\
$E$ & Overall Efficiency & $\%$ \\
$G$ & Daily solar radiation & $\mathrm{kJ} . \mathrm{m}^{-2} \cdot \mathrm{hr}^{-1}$ \\
$A$ & Aperture area of the collector & $\mathrm{Meter}^{-1}$ \\
\hline
\end{tabular}

\section{Introduction}

Hydroelectric and thermal solar energy has huge potential sources of renewable energy. Pakistan is the thriving renewable energy sources i. e. solar energy, biomass and wind energy etc, but for the development of country the utilization of solar energy is most important $[15,16,17]$. In Pakistan solar energy has very huge in amount and earth received a greater amount of energy from the sun 
throughout the year of about $7000 \mathrm{MJ} . \mathrm{m}^{-2}$ and $34^{\circ} \mathrm{N}$ latitude and $71^{\circ} \mathrm{E}$ longitude of Peshawar (Pakistan) received a $20 \mathrm{MJ}^{-\mathrm{m}^{-2}}$.day ${ }^{-1}$ energy from the sun [4, 13]. For the using of this huge amount of energy for the different purposes of i.e. drying and water heating etc, the best choice is solar collectors $[3,7]$. A solar collector is a device which converts sun energy into thermal energy which is used for drying of different types of fruits \& vegetable and also for heating of water [5, 10]. Water is the most important thing for human life to survive in the earth $[18,19]$. There is necessity of clean, drinkable and pure water for the surviving of human being in many countries, but there is brackish, harmful and containing impurities i. e. $\mathrm{Ca}, \mathrm{Mg}, \mathrm{NaCl}$ and $\mathrm{Zn}$ in the water resources [20, 21]. [24] Studied that solar energy is one of the promising techniques for getting the pure and clean water from potable water resources. For getting pure and clean water from the potable water resources, there are so many techniques which are used for heated water to produce clean and pure water i. e. solar collector, solar photovoltaic etc [25, 26].

Renewable energy donates clean, nontoxic energy source and the primary sources of energy are the sun, wind, biomass, waves and geothermal energy [18, 27]. Sun energy can be utilized in the form of thermal energy with the using of solar collectors for different purposes of i.e. water heating, drying, distillation and producing electricity etc $[3,22]$. Solar collectors are the best techniques for the production of heated water from the potable water [15]. A FPC is the best choice for heating of water with convective heat flow having an efficiency of $35 \%$ to $45 \%$ which is the least expensive and time saving technique $[6,7]$. Several years of research shown that FPC is the best technique for the using of heating of farm shops, dairy buildings and water heating [1]. For the using of FPC for heating of water, the key important parameter is its efficiency $[5,6]$. The efficiency of the collector depends on the optimum combination of temperature and flow rate [10].

The shortage of pure, clean and drinking water in many countries is the serious problems. Human being has to depend for rivers, sea water and underground water reservoirs for its fresh water needs, but these resources are more saline and cannot be drinkable [20]. To resolve this problem, different techniques of solar heating have been used in different countries. To use a FPC efficiently for heating of water, the optimization of the collector area, fluid flow rate and ambient temperature of the collector will give a result in greater efficiency [14]. In the present research study, we accentuate on the performance of FPC and its efficiency and developed for the production of heated water for the commercial use. The specific objective of this study was, to study the performance and efficiency of the FPC with the study of heating of water.

\section{Methods and Materials}

\section{Solar Radiation}

The Mechanical Pyranometer is in an instrument which give sun rays reading in chart, which falling directly on the instrument. The data which are recorded in the chart from the incoming sun rays multiplied with the constant $0.88\left(\mathrm{cal} . \mathrm{cm}^{-2} \cdot \mathrm{min}^{-1}\right)$ which give reading per minute. Further converting this data in to a standard unit, multiply with constant $418\left(\mathrm{~kJ} \cdot \mathrm{m}^{-2} \cdot \mathrm{min}^{-1}\right)$, calculating solar radiation the following Eq. 1 is used.

$$
I_{s}=0.88 \times 418 \times \mathrm{CV}
$$

\section{Assembling of Solar Water Heating Unit}

For the experiment of SWH purposes we used FPC with water tank, which is used for both purposes (cooled and hot water) during the experimental work showed in Fig. 1.

\section{Flat Plate Collector}

The FPC consists of a glass, heating transfer fins (absorbing sheet, made from aluminum material) and heating pipes. The heating pipes which were used in the collector having the length and diameter of $1.52 \mathrm{~m}$ and $0.076 \mathrm{~m}$ which are made of reflective mirror and steeliness steel respectively. These tubes were inter-connected with each other; from this the cold water passed within heating 
pipes and heated the water with the absorbing of sun irradiance with the help of glass because they are good radiated heat, cheap, easily available in the local market, having a high melting point and have low weight shown in Fig. 1.

\section{Hot Water Tank}

The hot water tank, having length and diameter is $1.212 \mathrm{~m}$ and $0.106 \mathrm{~m}$ respectively, made from steel sheet, used for storage of water (cold and hot water) and inlet and outlet pipe (Diameter $=0.762 \mathrm{~m}$ ) was made up of P.V.C fixed with the storage tank showed in Fig. 1. Inlet was fixed at the bottom of the tank for the cold water providences to the collector, while the outlet was fixed at the top of the storage tank due to the low density of the hot water. These pipes were connected with the FPC from the one side of the heating pipes. This water passed from the pipes and heated with the help of sunlight and in these heated water stored in the storage tank. The outlet was provided at the top of FPC because hot water goes up to due to the low density. Both the inlet and outlet duct have a cross sectional area of $0.912 \mathrm{~m}^{2}$.

Fig. 1. Isometric view of FPC assisted for SWH

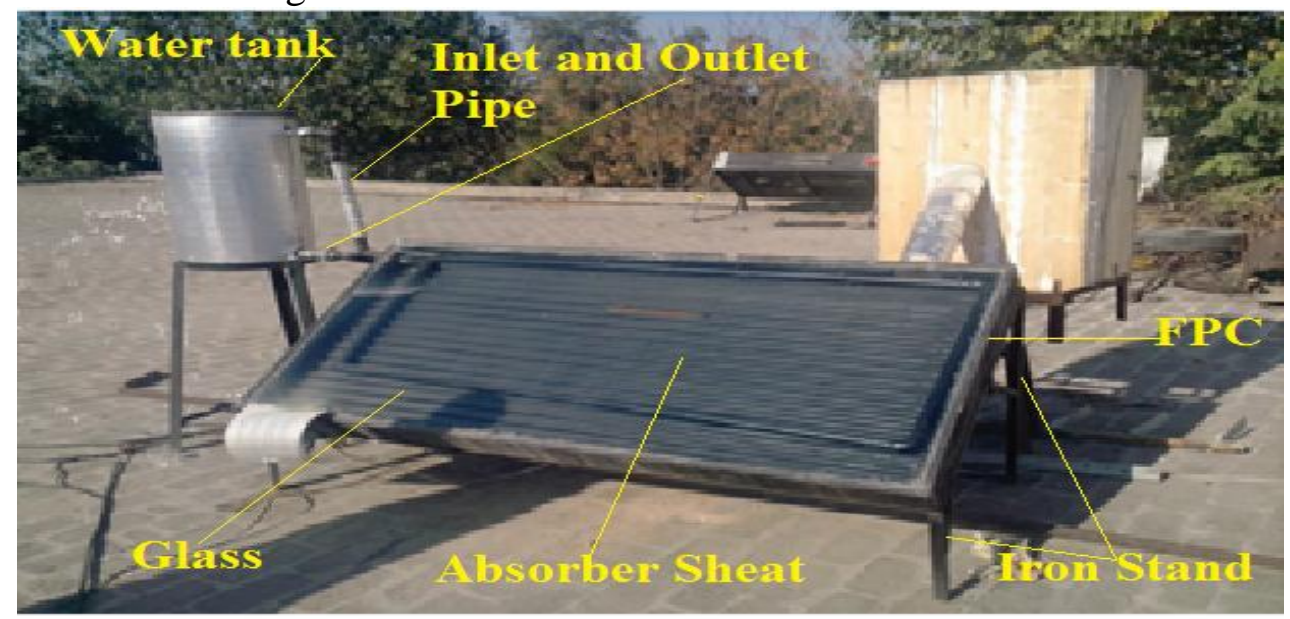

\section{Collector Tilt Angle}

The collector was fixed with the tilt angle of $35^{\circ}$ facing North-South axis, with the horizontal plane surface of the experimental site. The collector received maximum solar irradiance due to the azimuth and zenith angles of the sun which falls on the collector surface. As the experimental site is suited at the latitude of $34^{\circ}$ received maximum solar radiation from the collector which was tilted to $35^{\circ}$ so that the incident solar irradiance was normal to the collector surface.

\section{Recorded the Data}

The solar radiation data were recorded daily, weekly and monthly basis with the help of Mechanical Pyranometer in the form of a graph or chart [4]. The ambient and collector temperature was recorded with the help of digital thermometer by the method of [2]. The Efficiency of FPC was calculated from the Eq. 2, which is the ratio of the output of water to the input of solar energy in the collector which is recorded in percentage (\%) and volume of the heating pipe and water tank was calculated by using the equation 3 , by the method of $[4,5]$.

$$
\begin{aligned}
& \eta(\%)=\frac{\text { Mass of water }(\mathrm{Kg})}{\text { Solar energy }(\mathrm{kJ})} \times 100 \\
& V=\pi R_{a b}{ }^{2} L_{a b}
\end{aligned}
$$

\section{Performance of Flat Plate Collector}

The performance of FPC is the total amount of heating water in liters daily basis. The energy required to evaporate the water is $2.3 \mathrm{MJ}$ per kilogram. The efficiency and performance of FPC can 
be expressed as the fraction of total solar radiation falls on the collector and that actually heated up the water to the vaporization stage. There is so many techniques to be used for the production of heated water and can be calculated with the using of following Eq. 4.

$$
Q=\frac{E \times G \times A}{2.3}
$$

\section{Results and Discussions}

\section{Solar Radiation Intensity}

The average total solar radiation intensity were recorded for each month of the year-2014 in the range of $4580 \mathrm{~kJ} \cdot \mathrm{m}^{-2} \cdot \mathrm{hr}^{-1}$ to $2708 \mathrm{~kJ} \cdot \mathrm{m}^{-2} \cdot \mathrm{hr}^{-1}$ as shown in Fig. 2. The average maximum solar radiation intensity was recorded at $4580 \mathrm{~kJ} \cdot \mathrm{m}^{-2} \cdot \mathrm{hr}^{-1}$ for the month of June, followed by $4365 \mathrm{~kJ} . \mathrm{m}^{-}$ ${ }^{2} \cdot \mathrm{hr}^{-1}, 4288 \mathrm{~kJ} \cdot \mathrm{m}^{-2} \cdot \mathrm{hr}^{-1}$ for the month of July and August respectively, while the average minimum solar radiation intensity was noted in $3192 \mathrm{~kJ} \cdot \mathrm{m}^{-2} \cdot \mathrm{hr}^{-1}$ and $2708 \mathrm{~kJ} \cdot \mathrm{m}^{-2} \cdot \mathrm{hr}^{-1}$ in the month of November and December respectively, due to the low sunshine and rainy days. Similarly in the month of October the average sun radiation intensity was recorded $3587 \mathrm{~kJ} . \mathrm{m}^{-2} \cdot \mathrm{hr}^{-1}$ due to low sunshine. In Fig. 2, the solar radiation intensity of each month of the year showed the difference due to the azimuth and zenith angles, which changed in the months of the year of the sun rays incident on the solar collector. The results of solar radiation intensity are related to the findings of [9], who noted $3567 \mathrm{~kJ} . \mathrm{m}^{-2} \cdot \mathrm{hr}^{-1}$ solar radiation intensity in the months of October to December. The average total solar radiation intensity is high at $12: 00$ Noon observed $[6,7]$. The collector is used for collecting solar energy in the form of heat for heating of water from 9:00 AM to 4:00 PM. The graph showed that the distribution is normal with chi square value of 0.934 and $\mathrm{P}=0.923$. The analysis of the data showed that a linear model equation is fitted for the data and their interrelationship between the months of the year- 2014 .

Fig. 2. Solar Radiation Intensity Recorded for the consequently months of the Year-2014

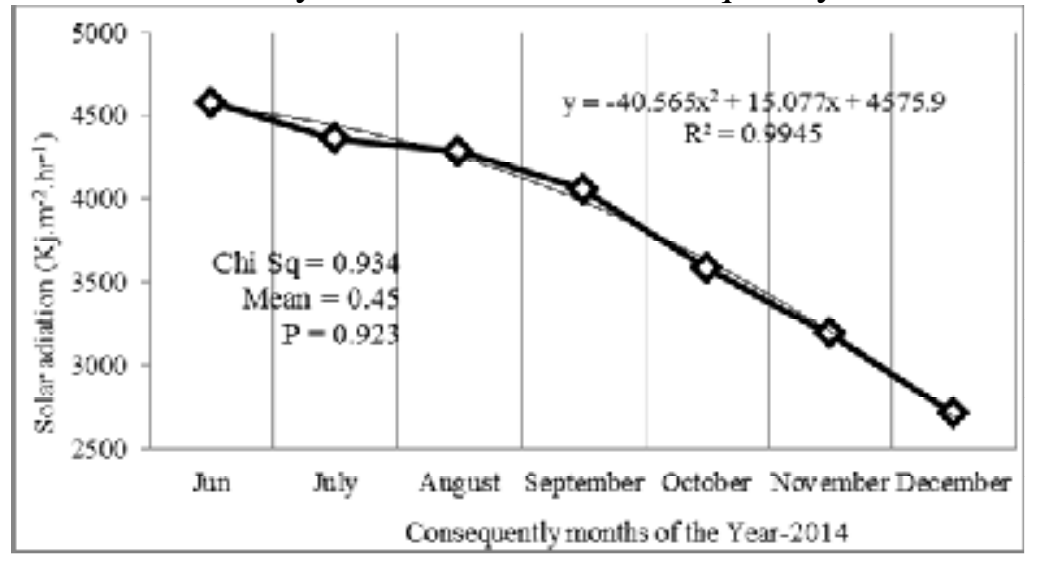

\section{Efficiency of the Flat Plate Collector}

Efficiency is the ratio of heat input and output of the collector. Efficiency of the FPC was evaluated for the consequently months of the year i.e. June to December with the ambient temperature level of $25^{\circ} \mathrm{C}$ was shown in Fig 3. Maximum efficiency was noted $37.29 \%$ in the month of July, followed by $36.97 \%, 36.54 \%$ and $36.20 \%$ for the month of June, August and September respectively due to high intensity of the sun and highly sunny days. The results are nearly closer with the finding of [12], while for the month of October the efficiency was noted of $25.14 \%$ which closer to the finding of $[20,21]$. Data were analyzed and found the efficiency of FPC with the significant interval difference $(\mathrm{P}<0.8361)$ and the data were fitted with a linear model equation. From the figure, $\mathrm{R}^{2}$ value showed that there is inter relationship between the months of the year. Figure 3, showed that the lowest efficiency of the collector were recorded in the months of December of $20.11 \%$ due to the 
low sun shine and also with the rainy days in this month of the year due to angle of the sun incident (which rays don't strike on the collector) which are similar results with the finding of $[5,12]$.

Fig. 3. Efficiency (\%) of FPC for the consequently months of the Year-

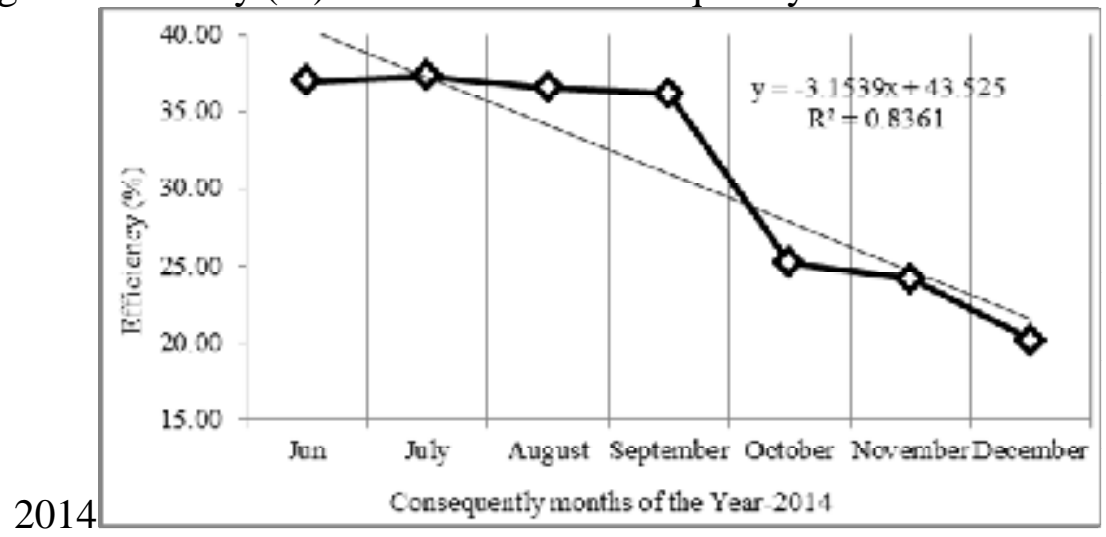

\section{Performance of Solar Water Heating Unit}

\section{Output of Heated Water}

In the Fig. 4, shows the average values of the output heated water for the consequently months of the year-2014, and the data were recorded in liter per month. The highest value of heated water were noted in the month of June and July of $16930 \mathrm{l} /$ month and $16277 \mathrm{l} / \mathrm{month}$ respectively which is similar with the finding of $[1,16]$, followed by the highest of $15670 \mathrm{l} / \mathrm{month}$ and $14679 \mathrm{l} / \mathrm{month}$ for the months of August and September. Similarly the lowest output heated water were noted for November of $12565 \mathrm{l} / \mathrm{month}$, followed by the least output of $12850 \mathrm{l} / \mathrm{month}$ and $12813 \mathrm{l} / \mathrm{month}$ were noted for the month of October and December respectively which is closer with the finding of $[7,11]$ due to the cloudy days in these months of the year. Data were analyzed and found that the linear model equation is fitted with data of heated water for the months of the year with the significant interval difference $(\mathrm{P}<0.9836)$. From the figure, $\mathrm{R}^{2}$ value showed that there is inter relationship between the months of the year. The collector was fixed with the angles of $34^{\circ}$ with the latitude of the location for the whole experiments. So that's why the output of heated water graph was lower and higher due to the sun tracking angles and sun rays which falling on the collector daily.

Fig. 4. Output of heated water for the consequently months of the year-2014

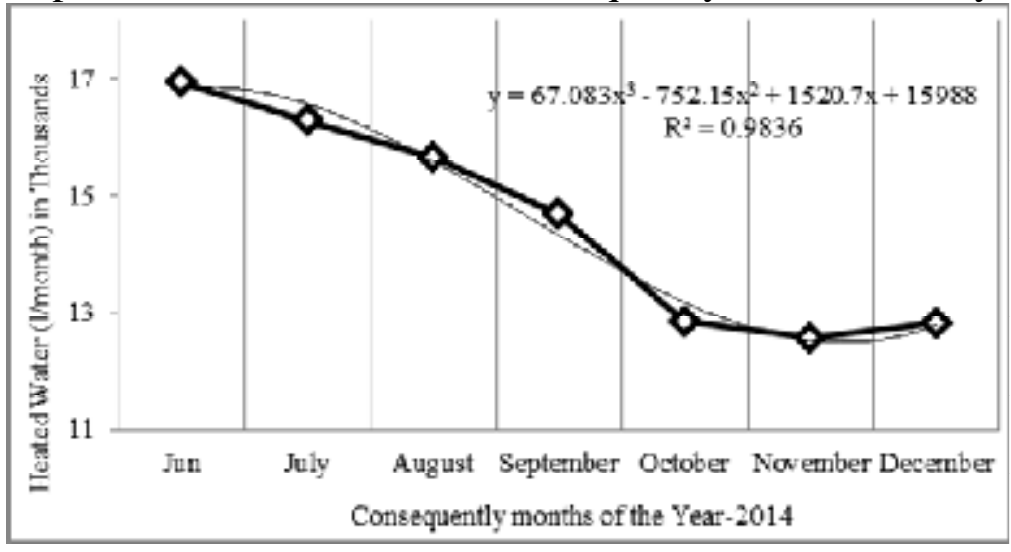




\section{Conclusions}

FPC has been fabricated with the locally available market materials and experimentally tested with the normal flow rate of water. The results of the experiment, it was concluded that efficiency of the FPC increased significantly with the increasing of solar absorbing irradiance. Further it was concluded that the efficiency of the collector was increased with the angle of the collector focus on the sun azimuth angle. Furthermore, from the experiment it was also concluded that output of heated water increased with the increased absorbance of sun radiation.

\section{Recommendation}

From the experiment, we have done the following recommendation and suggestion, that FPC is a cheap source of making SHW as compared to electrical heated plant. The collector should be focused on the zenith and azimuth angle of the location and also placed in open space for absorbing maximum solar radiation to get maximum heated water. Further from the experimental results, it was recommended that FPC works efficiently for 7 hours from 09:00AM to 04:00PM for the consequently months of the year-2014 i.e. June to December. Furthermore, suggested from the results that for increasing the collector efficiency, sensor revolving system should be developed with reference to direct reflection of sun rays.

\section{Acknowledgement}

I wish to all authors acknowledge and all contributors who supported me during research work and give their input during the research period and also special thanks to the College of Engineering, Nanjing Agricultural University, Nanjing, China. I am thankful for my parents and life partner to support me during research work and special thanks to Prof. Kang Min for the encouragement to write the paper. This work was edited for proper English language, grammar, punctuation, spelling, and overall style by native English speaking editors at American Journal Experts (AJE).

\section{REFERENCES}

[1] M.C. Ashraf, R. Raza and S.A. Hayat: Renewable energy technologies in Pakistan: Prospects and challenges, J. Renewable and Sustainable Energy Reviews. 13(9): 1657- 1662. (2009).

[2] B. Ma, J.S. Guo, C. Richard, Smardon, C. Jing: Diffusion of solar water heaters in regional China: Economic feasibility and policy effectiveness evaluation. J. Energy Policy. 72: 23-34. (2014).

[3] C.C. Chien, C.K. Kung, C.C. Chang, W.S. Lee, C.S. Jwo and S.L. Chen: Theoretical and experimental investigations of a two-phase thermosyphon solar water heater. J. Energy 36: 415423. (2011).

[4] U. Fahim, K.K. Mansoor and K. Maazullah: Development and Performance of Parabolic Trough Solar Water Distillation Unit. M.Sc. Thesis (unpublished). Deptt. of Agricultural Mechanization. Agric. Uni. Peshawar. (2013).

[5] U. Fahim, K.K. Mansoor, K. Maazullah, H. Lubna and H. Kamran: Impact of the dehydration process on guava by using of the parabolic trough solar concentrator. PAK. J. FOOD SCI., 26(2), 2016: 92-97. (2016).

[6] U. Fahim, H. Kang, H. Lubna, X.S. Wang, N.H. Li, J. Yang, K.K. Mansoor: Impact of Drying Method of Figs with Small Scale Flat Plate Solar Collector. World Journal of Engineering. 08-0054. (2016).

[7] F. Struckmann: Analysis of a Flat-plate Solar Collector. Dept. of Energy Sciences, Faculty of Engineering, Lund University, Box 118, 22100 Lund, Sweden. (2008).

[8] F.A. Al-Sulaiman, M.Z. Ifras, A. Maimoon, G. Palanichamy, S.A. Al-Dini and M.A. Antar: Humidifi cation dehumidifi cation desalination system using parabolic trough solar air collector. J. Applied Thermal Engineering 75: 809- 816. (2015). 
[9] J. Huang, Pu. Shaoxuan, G. Wenfeng and Y. Que: Experimental investigation on thermal performance of thermosyphon flat-plate solar water heater with a mantle heat exchanger. $J$. Energy 35: 3563-3568. (2010).

[10] J. Dersch, T. Vogel, T. Polklas and C. Tümmers: Solar-only parabolic trough plants with high steam parameters. J.Energy Procedia 49: 1117-1126. (2014).

[11] K.K. Chong, K.G. Chay and K.H. Chi: Stud y of a solar water heater using stationary Vtrough collector. J. Rene. Energy 39: 207-215. (2012).

[12] A. Kaleta and K. Gornicki: Evaluation of drying models of apples, Int. J. Food. Sci. Tech. 16(2): 667-687. (2010).

[13] M. Hanif, K.K. Mansoor, Masood-Ur-Rahman, K. Maazullah, M. Amin and M. Ramzan: Performance Evaluation of a Flat Plate Solar Collector as a Drier for chillies and tomatoes. $J$. Sci. Tech. and Dev. 33 (2): 63-67. (2014).

[14] M. Faizal, R. Saidur, S. Mekhilef and M.A. Alim: Energy, economic and environmental analysis of metal oxides nanofluid for flat-plate solar collector. J. Ene. Conv. and Manag. 76: 162-168. (2013).

[15] O. Helal, B. Chaouachi and S. Gabsi: Design and thermal performance of an ICS solar water heater based on three parabolic sections. J. Solar Energy 85: 2421-2432. (2011).

[16] B.M. Santos, R. Quiroz and T.P.F. Borges: A Solar Collector Design Procedure for Crop Drying. Brazilian. J. Chemical Eng. 22(2): 0104-6632. (2005).

[17] Y.C. Soo Too, G.L. Morrison and M. Behnia: Performance of solar water heaters with narrow mantle heat exchangers. J. Solar Energy 83: 350-362. (2009).

[18] S. Anant, D. Buddhi and R.L. Sawhney: Solar water heaters with phase change material thermal energy storage medium: A review. Renewable and Sustainable Energy Reviews. 13; 2119-2125. (2009).

[19] K. Devanarayanan and K.M. Kalidasa: Integrated collector storage solar water heater with compound parabolic concentrator- development and progress. Renewable and Sustainable Energy Reviews 39; 51-64. (2014).

[20] N. Novak, L. Nebojsa and Dragan: Mean fluid temperature of the double exposure and the conventional Flat-Plate water solar collector's experimental results. 8th International Quality Conference, Center for Quality, Faculty of Engineering, University of Kragujevac. May 23rd. (2014).

[21] C. Hossein, A. Yahya, E. Esmaeil, Z.H. Saeid, H. Mahdi and K. Mostafa: Experimental Study on Thermal Efficiency of Flat Plate Solar Collector Using TiO2/Water Nanofluid. Modern Applied Science; Vol. 7, No. 10. (2013).

[22] H. Amir, A. Yahya and A.B. Amir: Experimental analysis of flat plate solar air collector efficiency. Indian Journal of Science and Technology Vol. 5 No.8; ISSN: 0974- 6846. (2012).

[23] M.K. Amir, M. Rahman, M. Hanif, I. Muhammad and S.S. Fahad: Development of a Small Scale Concentrating Parabolic trough Solar Collector for Drying Purposes. Engineering International, Volume 1, No 1. (2013).

[24] A. Luca, Tagliafico, S. Federico and D.R. Mattia: Dynamic thermal models and CFD analysis for flat-plate thermal solar collectors-A review. Renewable \& Sustainable energy reviews, DOI: 10.1016/j.rser.10.023. (2013).

[25] M.S. Hossain, R. Saidur, H. Fayaz, N.A. Rahim, M.R. Islam, J.U. Ahamed and M.M. Rahman: Review on solar water heater collector and thermal energy performance of circulating pipe. Renewable and Sustainable Energy Reviews 15; 3801-3812. (2011).

[26] S. Ruchi, K. Sumathy, E. Phillip and G. Jiawei: Recent advances in the solar water heating systems: A review. Renewable and Sustainable Energy Reviews.19; 173-190. (2013).

[27] C. Sudhir, P. Nimesh, N.P. Hitesh: A Critical Review on Solar Water Heater. International journal of advanced engineering technology. 2013/50-52. (2013). 